\title{
Culture de la vanille dans le sud de la Floride ${ }^{1}$
}

\author{
Alan Chambers, Pamela Moon, Vovener de Verlands Edmond et Elias Bassil; translated by \\ Francesca Carla Erié ${ }^{2}$
}

\section{Nom scientifique: Vanilla planifolia}

Nom commun: Vanille

Famille: Orchidaceae

Origine: Méso-Amérique

Distribution: Globalement entre les latitudes $27^{\circ} \mathrm{N}$ et $27^{\circ} \mathrm{S}$.

\section{Résumé}

L'extrait de vanille est populaire dans le monde entier comme ingrédient dans la crème glacée et divers autres desserts. La source botanique de l'extrait de vanille provient principalement des gousses durcies (préparées) de l'espèce Vanilla planifolia. Les États-Unis sont les plus grands importateurs mondiaux de gousses de vanille, mais la production nationale est très faible. Toutefois, le sud de la Floride a un potentiel de production favorable à la culture de la vanille. Ce document contient des informations utiles aux producteurs intéressés par l'établissement d'une vanillerie.

\section{Histoire}

Les capsules de graines de vanille (communément appelées gousses de vanille) sont appréciées depuis longtemps pour leur arôme et leur saveur distincts. La principale espèce commerciale est $V$. planifolia. La $V . \times$ tahitensis vient après mais à une plus faible échelle. Madagascar est le premier producteur mondial de vanille avec l'Indonésie, l'Ouganda, l'Inde, les Comores, le Mexique et certains autres pays qui contribuent de manière significative à la production mondiale. Les États-Unis sont les plus grands importateurs de gousses de vanille qui sont ensuite transformées en extrait de vanille. L'extrait de vanille est maintenant largement utilisé dans les glaces (crème glacée), la pâtisserie, le chocolat, les produits cosmétiques et de nombreux autres produits.

V. planifolia s'est propagé de son aire de répartition d’origine en Méso-Amérique à travers les îles des Caraïbes, jusqu’en Europe et dans le monde vers la fin des années 1500.

Puisque la vanille est une espèce qui tolère les climats tropicaux et subtropicaux, les climats plus froids reposaient sur la culture de vanille dans des serres pour maintenir sa production. Les lianes nétaient pas productives en dehors de la gamme indigène en l'absence de pollinisateurs naturels. Le développement de méthodes de pollinisation manuelle en 1837 et 1841 par Charles Morren et Edmund Albius, respectivement, a permis d'exploiter le potentiel de

1. This document is HS1351, one of a series of the Horticultural Sciences Department, UF/IFAS Extension. Original publication date November 2019. Visit the EDIS website at https://edis.ifas.ufl.edu for the currently supported version of this publication. The English version of this publication is HS1348, Vanilla Cultivation in Southern Florida.

2. Alan Chambers, assistant professor, Horticultural Sciences Department; Pamela Moon, biological scientist III; Vovener de Verlands Edmond, graduate student; and Elias Bassil, assistant professor, Horticultural Sciences Department; UF/IFAS Tropical Research and Education Center, Homestead, FL 33031. Translated by Francesca Carla Erié.

The Institute of Food and Agricultural Sciences (IFAS) is an Equal Opportunity Institution authorized to provide research, educational information and other services

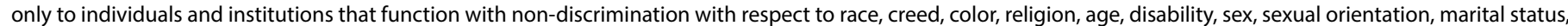

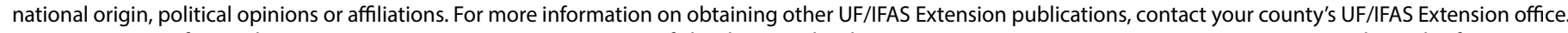
U.S. Department of Agriculture, UF/IFAS Extension Service, University of Florida, IFAS, Florida A \& M University Cooperative Extension Program, and Boards of County Commissioners Cooperating. Nick T. Place, dean for UF/IFAS Extension. 
cette espèce pour la production commerciale en dehors de la Mésoamérique. Ce développement opportun a favorisé une production accrue dans les années 1850 et 1860, en réponse aux contraintes d'approvisionnement du Mexique. Aujourd'hui, les descendants clonaux des plantes originales sont cultivés commercialement dans plusieurs pays.

La vanille est cultivée aux États-Unis depuis le début des années 1900 à Porto Rico, à Hawaii et en Floride. L'espèce V. planifolia a été introduite à Porto Rico à partir de la Floride à deux reprises avant 1909. L'industrie de la vanille à Porto Rico comprenait une association de producteurs. La station de l'USDA à Porto Rico a mené des recherches sur les pratiques horticulturales, la sélection, le traitement et la préparation des gousses de la vanille en appui à l'industrie de la vanille. À Porto Rico, l'industrie a connu une croissance jusqu'aux années 1950 et a connu un déclin après la Seconde Guerre mondiale, lorsque l'industrialisation a supplanté l'agriculture. Hawaii a reçu de la vanille dans le cadre de ses échanges commerciaux avant 1900. Hawaii produit toujours de la vanille, mais privilégie surtout le tourisme. En outre, la Floride compte quatre espèces de vanille indigènes ou endémiques $(V$. barbellata, $V$. dilloniana, $V$. phaeantha et $V$. mexicana) et aussi $V$. planifolia (non-endemique à la Floride) (Figura 1). Porto Rico compte sept espèces à croissance sauvage $(V$. barbellata, $V$. dilloniana, V. poitaei, V. pompona, V. claviculata, $V$. pompona et $V$. planifolia). Les espèces indigènes de vanille de Floride sont en voie de disparition et ne doivent pas être collectées dans des zones naturelles sans autorisation préalable et appropriée des autorités réglementaires.

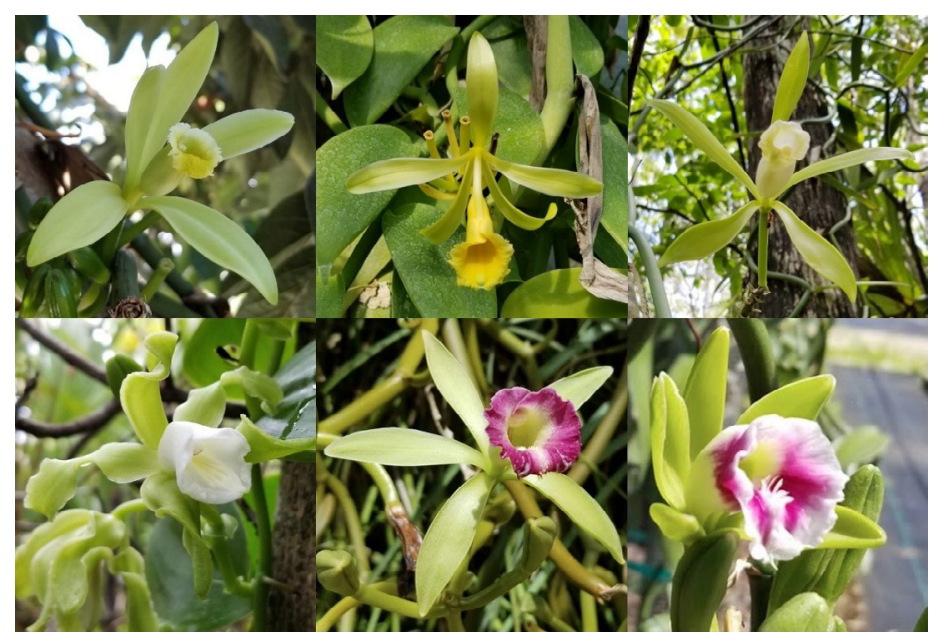

Figura 1. Fleurs de V. planifolia (en haut à gauche), de V. pompona (en haut au centre), de $V$. phaeantha (en haut à droite), de $V$. mexicana (en bas à gauche), de $V$. dilloniana (en bas au centre) et de $V$. barbellata (en bas à droite) poussant dans le sud de la Floride.

Créditos: Alan Chambers, UF/IFAS

\section{Importance}

Lextrait de vanille est la deuxième épice la plus précieuse (après le safran) et la saveur la plus populaire au monde. Lextrait de vanille naturel provient principalement des gousses séchées de $V$. planifolia, qui est la principale espèce commerciale, et dans une moindre mesure, il provient des espèces $V$. $\times$ tahitensis et de $V$. pompona. Les profils d'arôme et de saveur varient d'une espèce à une autre et varient aussi avec l'environnement de culture. Ces différences pourraient être utiles pour diverses applications, notamment en tant qu'ingrédients alimentaires, dans les cosmétiques et autres.

\section{Description}

\section{Plante}

V. planifolia est une liane charnue et vivace à tiges vertes. Les lianes vivent de nombreuses années et certaines espèces atteignent $60 \mathrm{~m}$ de long. Le diamètre de la tige augmente à mesure que la plante mûrit. La vanille est semi-épiphyte, ce qui signifie qu'elle est capable de s'enraciner dans le sol et de pousser sur d'autres plantes ou autre support sans contact direct avec le sol.

\section{Feuilles}

$V$. planifolia contient de brillantes feuilles vertes et succulentes. La taille des feuilles matures varie entre 8 à $25 \mathrm{~cm}$ ( 3 à 14 pouces) de long et de 2 à $8 \mathrm{~cm}$ ( 0,75 à 3 pouces) de large. En termes de morphologie, les feuilles de V. planifolia sont lancéolées à ovales, à bouts pointus et peuvent survivre environ 3 à 4 ans. Certains types de $V$. planifolia ont des feuilles panachées et sont généralement cultivés à des fins ornementales.

\section{Fleurs et fruits}

Les fleurs de V. planifolia sont grandes et parfumées. Des sépales vert crème cireux se forment sur les inflorescences axillaires. Les fleurs de V. pompona présentent une coloration jaune contrairement à celles de $V$. planifolia. Elles peuvent atteindre environ 6 à $8 \mathrm{~cm}$ (2,5 à 3 pouces) de longueur et environ 5 à $10 \mathrm{~cm}$ ( 2 à 4 pouces) de diamètre. Deux des pétales ont une apparence similaire aux sépales. Le troisième pétale est modifié en forme de lèvre. Ce dernier contient deux pollinies (masses de pollen) et le stigmate, montés sur une colonne. Une structure située entre le stigmate et les pollinies, appelée le "rostellum ", empêche efficacement l'autopollinisation.

Les fleurs sont formées en grappes axillaires avec quelques fleurs par grappe appelées racèmes. Ils apparaissent pour la première fois 2-3 ans après la plantation d'une nouvelle 
bouture. La vanille a tendance à fleurir sur les grandes vignes lorsque le diamètre atteint $6-13 \mathrm{~mm}(0,25$ à 0,5 pouce). En règle générale, une, mais parfois jusquà trois fleurs dans une grappe peuvent s'ouvrir à la fois, généralement tôt le matin. La floraison a généralement lieu sur une période d'environ 2 mois, une fois par an, mais chaque fleur de $V$. planifolia ne dure qu'un jour. Les fleurs de certaines autres espèces de vanille peuvent rester viables plus longtemps que la V. planifolia.

Après la pollinisation, l'ovaire gonfle pour donner une longue capsule de graine (fèves ou gousses) pouvant atteindre environ $20 \mathrm{~cm}$ de long et mettre entre 8 et 9 mois pour mûrir. Les gousses de vanille contiennent des milliers de petites graines noires et rondes. À maturité, la fève (gousse) de vanille se fend le long de deux coutures longitudinales, exposant les graines et les réduisant à des fins commerciales.

\section{Racines}

La vanille contient deux types de racines : les racines aériennes et les racines terrestres. Les racines aériennes ne sont généralement pas ramifiées et se forment sur la tige opposée aux feuilles. Les racines aériennes ont principalement pour fonction de faciliter aux lianes de vanille de grimper et sont donc très efficaces pour adhérer aux plantes ou structures de support. Les racines terrestres, se trouvant généralement à la base de la vigne, sont ramifiées et possèdent des poils absorbants souvent associés à des mycorhizes. Comme pour les autres racines terrestres, le rôle principal de ces racines est d'absorber l'eau et les éléments nutritifs du sol.

\section{Pollinisation}

Lautopollinisation des fleurs de V. planifolia est rare, voire inexistante, dans les régions où les pollinisateurs indigènes (abeilles et peut-être même les colibris) ne sont pas présents. Bien que nétant pas endémique à la Floride, l'Euglossa dilemma (abeille d'orchidées) (Figura 2) s'est établie dans le sud de la Floride et pourrait potentiellement être un pollinisateur de la vanille. Sinon, nos observations dans les zones naturelles montrent que les espèces de vanille indigènes produisent des fruits en l'absence de pollinisation manuelle (Figura 3 ). Une hypothèse est qu'un pollinisateur d’orchidées indigènes au sud de la Floride pourrait également polliniser des fleurs de V. planifolia, réduisant ainsi le besoin de pollinisation manuelle.

V. planifolia est généralement auto-compatible, ce qui signifie que le pollen d'une fleur peut être utilisé pour fertiliser la même fleur et conduira au développement des graines et des fèves. La pollinisation serait faible (environ
1\%) dans l'aire de répartition mexicaine, même en présence de pollinisateurs. Ainsi, la production commerciale de vanille est fortement tributaire de la pollinisation manuelle.

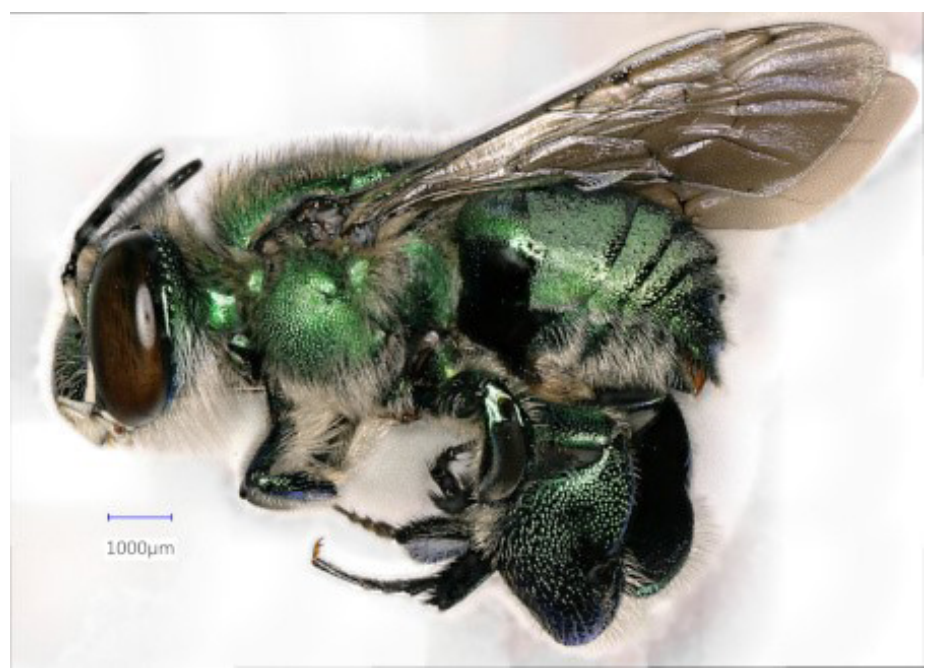

Figura 2. L'Euglossa dilemma a été attirée et capturée au « UF/IFAS Tropical Research and Education Center (TREC) ». Cette abeille pourrait être un pollinisateur de la vanille. Créditos: Daniel Carrillo, UF/IFAS

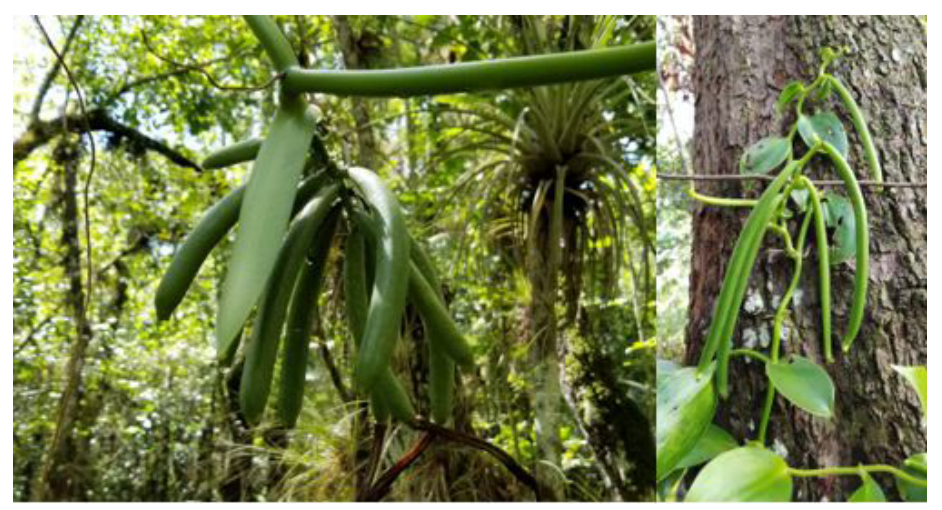

Figura 3. Développement des fruits (fèves ou gousse de vanille) en l'absence de pollinisation manuelle de $V$. phaeantha (à gauche) et de $V$. mexicana (à droite) dans des zones naturelles.

Créditos: Alan Chambers, UF/IFAS

Pour polliniser une fleur de vanille, il faut contourner le « rostellum » qui sépare les pollinies (groupe de pollen) et le stigmate. Les pollinisations doivent avoir lieu le matin, généralement entre 6 heures et midi. La pollinisation manuelle peut être réalisée à l'aide d'un cure-dent ou d'un autre instrument étroit similaire. Une section des fleurs de $V$. planifolia et $V$. pompona est illustrée à la figure 4 pour faciliter la description de la pollinisation. Le pétale inférieur peut être déchiré pour exposer les anthères avec le pollen (pollinie), le rostellum et le stigmate. Le rostellum est doucement poussé vers le haut et éloigné des stigmates jusqu'à ce que le rabat de pollinie puisse être poussé vers les stigmates et établir un contact doux avec eux. Si la pollinisation est réussie, la fleur sera retenue sur la plante, sinon elle tombe généralement dans 2-3 jours. Les fèves commencent 
rapidement à gonfler et à s'allonger en quelques semaines si elles sont correctement pollinisées.

À des fins commerciales, seules les fleurs situées sur le côté inférieur de la grappe sont pollinisées. Les gousses qui y sont produites deviendront droites et ont un prix supérieur. Si la plante est vigoureuse, un total de 8-12 fleurs sur 10-20 grappes peut être pollinisé. Environ 10 gousses par grappe sont souhaitables.

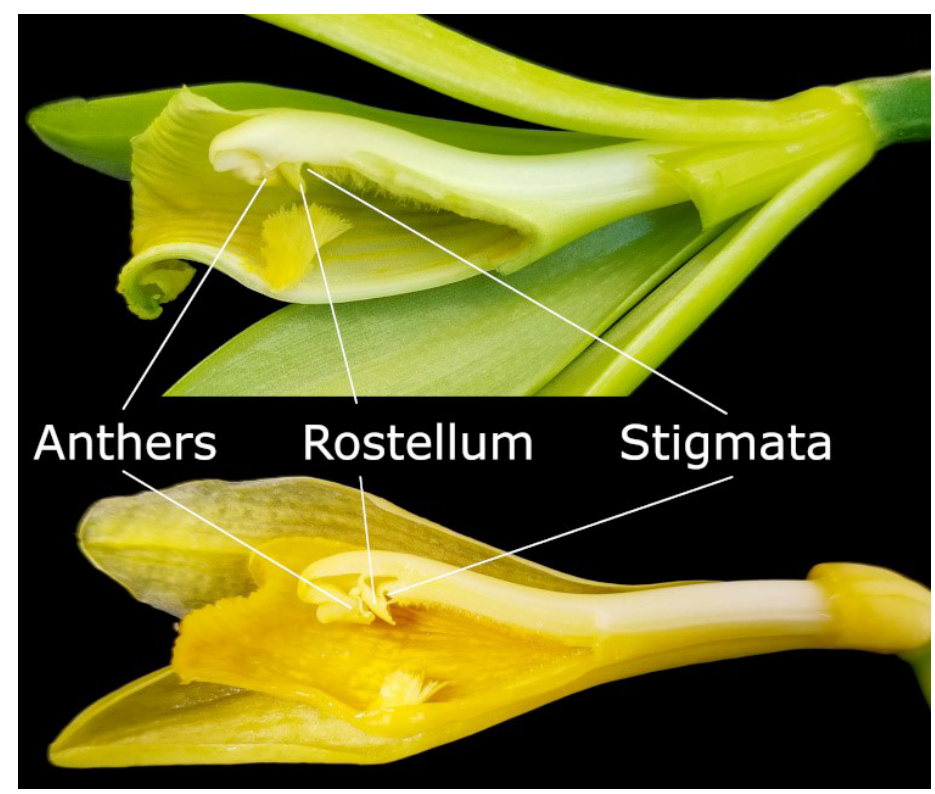

Figura 4. Fleurs de V. planifolia (en haut) et de V. pompona (en bas) avec anthères (pollinies), rostellum et stigmates. Les stigmates sont protégés directement derrière le rostellum.

Créditos: Alan Chambers, UF/IFAS

\section{Variétés}

L'espèce $V$. planifolia n’a généralement pas bénéficié de la sélection végétale moderne, il existe donc peu de cultivars nommés. Un seul cultivar, «Handa », a été breveté. Cette variété a été mise au point par des chercheurs de « La Réunion » et la disponibilité future de ce matériel est inconnue. Sinon, quelques types distincts de V. planifolia ont été caractérisés. Ceux-ci comprennent les types " Mansa » originaires du Mexique et couramment cultivés à des fins commerciales. Il existe également deux types de $V$. planifolia panachée, généralement disponibles en ligne et cultivés uniquement à des fins ornementales.

Lespèce $V$. $\times$ tahitensis est le deuxième type de vanille cultivé à léchelle commerciale. Notre compréhension actuelle est que la $V . \times$ tahitensis est principalement un hybride de $V$. planifolia génétiquement avec un peu de $V$. odorata (une autre espèce de vanille) dans son ascendance. Le « $x$ » indique qu'il s'agit d'un hybride et non d'une espèce distincte. La contribution génétique de $V$. odorata à $V . \times$ tahitensis semble être mineure, mais elle a des impacts majeurs sur le fendage et aussi sur l'arôme des fèves/ gousses. Les notes de saveur d'anis augmentées de ce type sont populaires dans les desserts français. Les boutures prétendant être $V . \times$ tahitensis peuvent être achetées en ligne, mais nos recherches ont montré que de nombreux fournisseurs en ligne vendaient sans le savoir (espérons-le) $V$. planifolia comme $V . \times$ tahitensis. La plupart des sources internationales de $V . \times$ tahitensis vérifiées ne sont pas disposées à partager leur matériel. Des recherches sont en cours pour vérifier et distribuer $V$. $\times$ tahitensis aux producteurs intéressés.

Il existe également des risques associés à l'achat de plantes mères qui ont des qualités indésirables, notamment des types stériles, à faible rendement ou de mauvaise qualité. Nombre d'entre elles produiront la vigne et les fleurs d'une beauté classique, mais ne sont pas optimales pour la culture commerciale. Malheureusement, les sources de ces types sont difficiles à identifier en raison du temps nécessaire pour obtenir une vigne mature avec des fleurs. Des recherches sont actuellement en cours pour identifier les types de vanille pouvant produire de manière constante des gousses à des fins commerciales afin de réduire les risques pour les producteurs.

$V$. pompona est couramment cultivé dans le sud de la Floride par des amateurs et est également confondu avec $V$. planifolia. V. pompona est vigoureux, mais produit apparemment une essence de vanille de qualité inférieure. Leurs fleurs présentent une couleur jaune comparée à la couleur vert crème des fleurs de $V$. planifolia.

\section{Conditions environnementales}

Le sud de la Floride, avec son climat chaud et humide, offre des opportunités à la culture de la vanille. La vanille est sensible au froid, notamment au gel. Par conséquent, un endroit présentant un risque réduit de gel doit être sélectionné pour la culture de la vanille. Des précipitations optimales pour la vanille ont été signalées autour de 170 à $280 \mathrm{~cm}$ par an (67 à 110 pouces / an). La vanille nécessite environ deux mois de saison sèche pour commencer la floraison. Des conditions excessivement humides pendant la maturation des fruits peuvent entraîner la pourriture des gousses. L'irrigation d'appoint peut être utile pour la création de nouvelles boutures et éventuellement pour la protection contre le gel. La Figure 5 présente les précipitations et les températures mensuelles moyennes enregistrées par la station météorologique FAWN du centre de recherche et d'éducation tropicale de l'Université de Floride (TREC). 


\section{iill lll|lii}

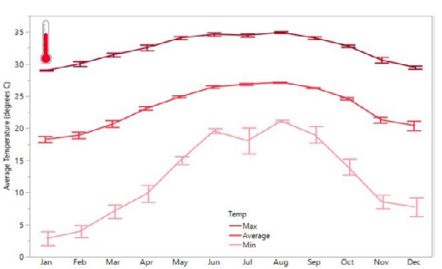

Figura 5. Précipitations mensuelles moyennes et températures maximales, moyennes et minimales à Homestead, Floride. Les données sont des moyennes sur 10 ans de 2006 à 2016.

\section{Propagation}

La vanille se multiplie principalement par boutures. Il est important de laisser les sites de coupe guérir avant la plantation en exposant les boutures fraîches à la température ambiante sous un faible éclairage pendant 1 à 2 jours. Tous les autres facteurs étant égaux, plus la coupe est longue, plus la vigne s'établit et commence à fleurir rapidement. Les boutures de $30 \mathrm{~cm}$ (12 po) de long ont généralement besoin de 3 à 4 ans pour fleurir, alors que les boutures d'un mètre (1m) devraient fleurir dans 2-3 ans.

Les boutures peuvent être placées directement sur le substrat de croissance (paillis de différentes sources) dès que les sites de coupe sont cicatrisés. La brumisation aidera les vignes à conserver leurs feuilles et favorisera le développement rapide de nouvelles racines et pousses. L'extrémité apicale des boutures plus longues peut être attachée à un poteau de support avec uniquement les deux nœuds distaux (1-2) en contact avec le substrat ou légèrement recouverte par celui-ci. Les feuilles doivent être retirées des nœuds en contact avec le paillis.

Les plantules de $V$. planifolia issues des techniques de tissue culture sont disponibles auprès de quelques entreprises. Elles sont attrayantes en tant que source propre de produit de départ, mais requièrent 3 à 4 ans pour parvenir à maturité et fleurir. Les plantules de culture tissulaire, reçues généralement dans des récipients fermés, devront être durcies dans un mélange sans sol sous des dômes humides et exposées à une lumière indirecte pendant quelques semaines à quelques mois avant de pouvoir survivre dans un environnement peu humide et où l'air circule librement. Une brumisation légère et régulière augmentera la survie des jeunes plantes en culture tissulaire.

Le tégument épais et hautement lignifié enveloppant l'embryon empêche la germination en temps opportun et prend beaucoup plus de temps à se développer en plantes matures que les boutures. En outre, la germination des semences dépend probablement d'associations avec des champignons ou d'autres micro-organismes. De telles contraintes ont favorisé l'utilisation des boutures comme méthode de propagation prédominante.

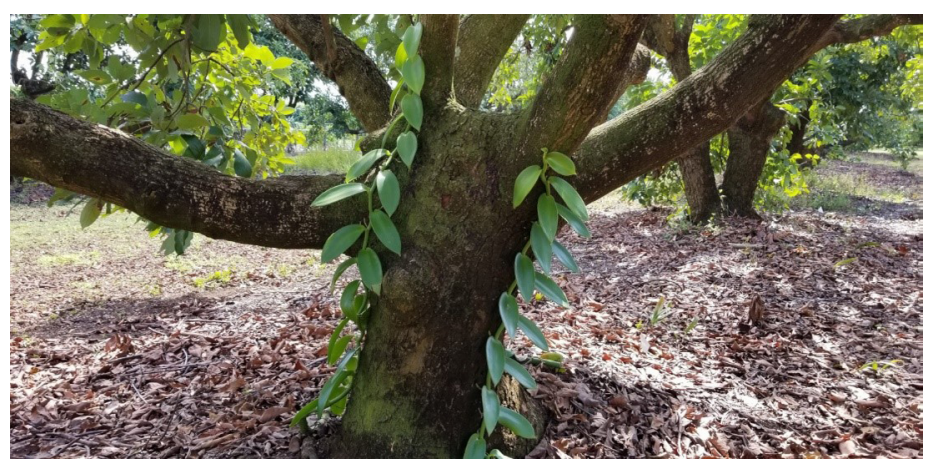

Figura 6. V. pompona poussant sur un avocatier. Les vignes ont été reçues en boutures d'environ 1 mètre. La croissance s'est effectuée après un an sans irrigation supplémentaire.

Créditos: Alan Chambers, UF/IFAS

\section{Méthodes de production}

Les lianes de vanille ont besoin de treillis pour maximiser la production. Deux grandes méthodes de production sont utilisées. On utilise des arbres « tuteurs » pour fournir à la fois de l'ombre et une structure appropriée sur laquelle les vignes peuvent grimper. Les arbres tuteurs peuvent être sélectionnés en fonction de la rusticité dans un endroit donné et aussi en fonction de la disponibilité et des considérations de cultures associées. Ce type de culture peut être moins cher dans certaines régions, et réduit également naturellement le risque de mortalités des plantules par Fusarium en augmentant la distance de plantation. Les producteurs du sud de la Floride devraient considérer la vanille comme une culture secondaire sur les arbres fruitiers existants. La Figure 6 montre des lianes de $V$. pompona poussant sur un avocatier. Tous les intrants agricoles devront être compatibles avec les deux espèces selon le modèle d'association de culture.

Une culture plus intensive sous les structures d'ombre peut conduire à une augmentation des rendements. Ce système nécessite un investissement initial plus important pour l'infrastructure. Cependant, il permet une augmentation de la densité de plantation et du potentiel de rendement. Les systèmes de soutien à treillis varient considérablement, mais sont généralement en bois vertical ou en béton avec du fil entre eux. Les treillis doivent avoir en général pas plus de $2 \mathrm{~m}$ de haut pour faciliter la pollinisation une fois que les lianes sont matures. La mise en place de système constitué de poteaux et de fils permet un meilleur contrôle de l'espacement des lianes par rapport aux arbres tuteurs. Les lianes devront être entretenues sur un substrat de paillis de 15 à $20 \mathrm{~cm}$. 


\section{Espacement et plantation}

On estime que 1000 plantes par acre (environ 2400 plantes par hectare) sont souvent utilisées pour créer une vanillerie commerciale. Les recommandations d'espacement sont de planter des lianes espacées de 1 à $3 \mathrm{~m}$ x 2,5 à $3 \mathrm{~m}$ entre les rangées.

\section{Les sols}

La vanille peut être cultivée dans un large éventail de types de sol, mais prospère dans les sols légers contenant beaucoup de matière organique. Pour la méthode de l'arbre tuteur, une légère pente peut être bénéfique pour réduire les incidences d'eau stagnante et d'occurrence de maladie. Les sols secs nécessiteront une irrigation supplémentaire pour maintenir une humidité adéquate du sol. Dans des systèmes de culture plus intensifs, l'humidité du sol peut être régulée en contrôlant la hauteur des lits de paillis surélevés.

Le paillis est un substrat populaire pour la culture de la vanille. Le type particulier de paillis n'est pas aussi important que sa capacité à libérer lentement les nutriments et à conserver un niveau optimal d'humidité pour les racines. Certaines régions comptent sur des coques et des feuilles de noix de coco vieillies pour le paillage des lianes de vanille. Le paillis devra être réappliqué tous les 6 à 12 mois pour reconstituer la source de nutriments et supprimer les mauvaises herbes. Il peut être appliqué directement sur le sol. Toutefois, il n'est pas nécessaire de l'incorporer en profondeur dans le sol.

\section{Élagage et formation}

Les lianes sont formées pour faciliter la pollinisation et la récolte à la main grâce à un processus appelé « bouclage ». Les lianes doivent entourer le treillis ou les branches pendant leur phase de croissance. Les boucles de lianes au sol stimuleront la formation de racines terrestres, surtout si elles sont recouvertes de paillis, ce qui donnera des lianes plus résistantes.

Des lianes saines en boucle issues de plantes matures peuvent être inclinées (apex enlevé) pour induire la floraison. Les pointes de lianes sont coupées à environ $15 \mathrm{~cm}$ de lextrémité (au-dessus de la ligne de sol) juste avant la saison sèche en vue de réduire la dominance apicale et d'induire la floraison dans les prochains mois.

\section{Irrigation}

Les cycles naturels de pluie en Floride sont favorables à la production de vanille. La saison des pluies et les températures estivales élevées stimulent une croissance rapide. La saison plus sèche induit une période de repos nécessaire avant la floraison. En conséquence, les plants de vanille établis peuvent parfois ne pas nécessiter d'irrigation supplémentaire, sauf pendant les périodes de sécheresse extrême. Les plants de vanille tolèrent de courtes périodes de dessiccation. L'irrigation est plus critique pour la production commerciale que dans le paysage domestique.

\section{Fertilisation}

La culture de la vanille repose sur la libération lente des nutriments contenus dans les matières organiques en décomposition. Une nutrition foliaire supplémentaire peut être appliquée, mais des tests scientifiquement validés pour justifier cet apport supplémentaire font encore défaut.

\section{Ravageurs/Pestes}

Les insectes nuisibles ne causent généralement pas de dommages graves. Les escargots et les limaces peuvent toutefois être problématiques s'ils ne sont pas contrôlés. Nous avons remarqué que les larves se nourrissent de jeunes plantes, mais les parasites peuvent être éliminés manuellement.

\section{Maladies}

Une des principales limitations à la production de vanille dans de nombreuses régions est la pourriture des racines et de la tige causée par le Fusarium oxysporum. Le fusarium est un champignon omniprésent dans le sol qui cause la pourriture chez de nombreuses espèces. Un type spécialisé (Fusarium oxysporum f. sp. radices-vanillae) provoque la pourriture de la vanille dans toutes les principales zones de production en pénétrant dans les racines et en se propageant dans toute la plante. Les symptômes typiques incluent le brunissement et le flétrissement, entraînant éventuellement la mort des lianes. La maladie peut être partiellement contrôlée par de bonnes pratiques horticoles, notamment en évitant l'utilisation excessive de l'eau. Les fongicides et les agents de lutte biologique peuvent présenter des avantages dans certaines conditions. Lanthracnose et le mildiou sont d'autres maladies fongiques potentielles.

\section{Récolte et traitement traditionnel}

Les fèves/gousses de vanille commencent à jaunir à la fin de la floraison lorsqu'elles sont complètement matures. Il faut prendre soin de ne pas les récolter prématurément car cela pourrait avoir un impact négatif sur la qualité de l'extrait de vanille obtenu. Les gousses de V. planifolia laissées trop longtemps sur les lianes ont une propension plus grande à se fendre ou à moisir. Ce qui élimine ainsi leur valeur 
économique. L'exception à cette règle est la $V$. $\times$ tahitensis qui naffiche pas le trait de fendage des gousses et peut être laissée sur la liane jusquà ce qu'elle soit complètement brune. Les gousses individuelles doivent être soigneusement retirées de la grappe afin déviter de les endommager.

Les gousses de vanille doivent être durcies afin de développer l'arôme et la saveur de vanille caractéristique. Les résultats du traitement varient considérablement selon l'endroit et sont fortement influencés par l'environnement de croissance, les facteurs génétiques et aussi la maturité des gousses. Le séchage des gousses de vanille reste un peu un art avec de nombreuses variations pratiquées dans différentes parties du monde. En général, le durcissement comprend quelques étapes principales : tri, mise à mort, transpiration, séchage progressif et conditionnement.

\section{Tri}

Les gousses sont triées en classes qui comprennent des gousses de $16 \mathrm{~cm}$ et plus, celles de $12-16 \mathrm{~cm}$ et les celles de petite taille, fendues ou rejetées. Le tri des gousses suivant leur taille est important pour l'étape de traitement thermique de la cuisson.

\section{Traitement thermique}

La chaleur est appliquée à une température suffisamment élevée pour tuer les cellules végétales, mais pas assez pour détruire les enzymes nécessaires à la production des arômes de vanille recherchés. Le traitement à l'eau chaude à une température de $63^{\circ} \mathrm{C}$ à $65^{\circ} \mathrm{C}$ est nécessaire pour arrêter le développement des cellules et commencer le processus de durcissement. Les gousses longues $(>16 \mathrm{~cm})$ doivent être chauffées pendant 3 minutes, celles de $12-16 \mathrm{~cm}$ pendant 2,5 minutes. Les petites gousses peuvent être traitées à l'eau chaude pendant 2 minutes en fonction des besoins pour le produit final. Après le traitement par la chaleur, les gousses sont emballées dans des sacs en plastique pour la transpiration.

\section{Transpiration}

La transpiration consiste à maintenir la température des fèves au-dessus de $45^{\circ} \mathrm{C}$ pendant 24 à 48 heures après le traitement thermique. Cela peut être fait en utilisant des boîtes isolées avec contrôle de température ou en plaçant des bouteilles contenant de l'eau chaude $\left(\sim 60^{\circ} \mathrm{C}\right)$ à l'intérieur du récipient isolé. Les gousses doivent être brun foncé après le traitement par l'eau chaude et la transpiration.

\section{Séchage progressif}

Le séchage lent des fèves jusquà un taux d'humidité final $<25 \%$ est important pour le développement des arômes et le contrôle de la croissance microbienne. Pour ce faire, il faut généralement retirer les fèves de leurs sacs en plastique pendant 12 à 15 jours, les exposer au soleil pendant quelques heures chaque jour et les reconditionner dans des sacs en plastique à la fin du traitement solaire. Ce processus pourrait être imité en utilisant des espaces dotés d'un contrôle de la température, de l'humidité et du débit d'air. Les gousses sont ensuite placées sur des plateaux ouverts pour continuer à sécher pendant environ 70 jours. Elles seront triées par qualité à la fin de létape de séchage. Toutes les gousses moisies doivent être jetées une fois détectée.

\section{Conditionnement}

Le conditionnement prend généralement un à deux mois. Les gousses empaquetées doivent être conditionnées dans des boîtes recouvertes de papier imperméable à la graisse et à l'huile (par exemple, papier ciré, papier sulfurisé). Les gousses ne doivent pas être complètement sèches pendant le conditionnement.

\section{Faire votre propre extrait de vanille (essence de vanille)}

Seuls les extraits de deux types de vanille, $V$. planifolia et $V$. $\times$ tahitensis, peuvent être vendus en tant qu ' " essence de vanille » en vertu du Code of Federal Regulations (Code of Federal Regulations, Titre 21 CFR169.175 et CFR169.3). Le règlement exige que le solvant pour l'extrait de vanille soit d'au moins $35 \%$ d'alcool éthylique par volume avec 13,35 onces de gousses de vanille à $25 \%$ d'humidité par gallon de solvant. Les petits producteurs voudront peut-être envisager de créer des entreprises coopératives pour améliorer les processus de séchage et d'entreposage et pour aider à assurer l'uniformité et la consistance des gousses de vanille séchées.

\section{Économie de base}

De nombreux producteurs potentiels souhaiteraient disposer d'estimations de base pour les principaux intrants lors de l'établissement d'une nouvelle vanillerie. Les données disponibles proviennent d'autres environnements de culture et de pratiques de production qui ne correspondront pas nécessairement à ceux des producteurs du sud de la Floride. Néanmoins, des estimations approximatives peuvent être utiles pour envisager une nouvelle opération de culture. Les réponses suivantes aux questions courantes sont fournies 
uniquement à des fins d'estimation et les résultats réels devront être déterminés de manière empirique.

\section{Réponses aux questions courantes}

Q: Combien d'années prend la liane de la vanille pour produire des fleurs et des gousses?

R: Les boutures de plusieurs mètres fleuriront au bout de 2-3 ans, et les plus petites boutures et les plantules provenant de culture tissulaire prendront 3-4 ans.

Q: Combien de fois une plante de l'espèce $V$. planifolia fleurit-elle par an et quand cela se produit-il ?

R: La vanille fleurit une fois par an, généralement d'avril à mai, dans le sud de la Floride.

Q: Combien de mois faut-il pour qu'une fève mûrisse?

R: Environ 9 mois après la pollinisation.

Q: Combien de kilogrammes de gousses vertes une plante de V. planifolia peut-elle produire? Quel est le poids en kilogramme d'une gousse séchée?

R: Un plant de vanille en bonne santé peut produire environ $2 \mathrm{~kg}$ de gousses vertes. Le traitement/durcissement conduit à un ratio généralement entre $5: 1$ ou 6 : $1 \mathrm{~kg}$ de gousses verte, de sorte que chaque plante peut produire environ 0,3 à $0,4 \mathrm{~kg}$ de gousses traitées.

Q: Combien de gousses séchées/traitées sont dans un paquet de $1 \mathrm{~kg}$ ?

R: Il y aura environ 200 à 400 fèves séchées dans un paquet de $1 \mathrm{~kg}$.

Q: Combien de plantes ai-je besoin par acre ou hectare?

R: Environ 1000 plantes par acre (env. 2400 par ha) est une bonne estimation, mais cela dépend de la méthode de production. Davantage de plantes sont nécessaires pour la culture intensive à l'ombre et moins de plantes lorsque vous utilisez des tuteurs.

Q: Où puis-je obtenir des plantes de V. planifolia?

R: Une recherche rapide sur Internet permet d'identifier les sociétés de tissu cultures situées en Floride et hors des États-Unis (par exemple, le Costa Rica). Vous devez veiller à ce que ces sociétés vendent $V$. planifolia ou $V$. $\times$ tahitensis si vous envisagez de vendre de $"$ l'extrait de vanille».
Q: Combien de travail est requis pendant la pollinisation?

R: Selon une estimation générale, une personne peut polliniser une acre $/ 0.40$ ha de plantation de vanille. Cela inclut la surveillance quotidienne des plantes pendant la saison de floraison afin de polliniser les fleurs fraîchement ouvertes.

Q: Les fleurs de vanille doivent-elles vraiment être pollinisées le matin de leur ouverture?

R: Oui, les fleurs de vanille ne sont réceptives à la pollinisation que pendant une courte période. Les températures peuvent avoir un impact sur la longévité des fleurs, mais la pollinisation avant midi est généralement optimale.

Q: Puis-je cultiver des hybrides vanille?

R: Bien sûr, mais le cadre réglementaire de certains hybrides est flou. Un producteur doit tenir compte de ses acheteurs et de ses consommateurs lorsqu'il envisage de cultiver des hybrides de vanille incorporant des espèces autres que $V$. planifolia et $V$. $\times$ tahitensis. Certains hybrides seront plus robustes et auront une plus grande résistance aux maladies que le $V$. planifolia traditionnel.

Q: Combien de fleurs doivent être pollinisées par grappe/ racème?

R: Normalement, il ne faut pas laisser plus de 10 gousses se développer par grappe. De plus, l'état nutritionnel de la liane pourrait être surchargé, ce qui pourrait nuire à sa santé l'année suivante.

Q: Combien de temps les lianes de vanille resteront-elles en production?

R: Cela dépend de la santé des lianes, des maladies et d'autres pratiques culturelles. Vous pouvez vous attendre à ce que les lianes restent productives pendant 3 à 5 ans, mais le cycle régulier avec de nouvelles lianes exemptes de maladies aidera à produire des gousses de manière durable.

\section{Ressources additionnelles}

Bianchessi, P. 2012. Vanilla Handbook. Technical Centre for Agricultural and Rural Cooperation.

Cameron, K. 2012. Vanilla Orchids: Natural History and Cultivation. Timber Press.

Childers, N. F. 1948. Vanilla Culture in Puerto Rico. US Department of Agriculture, Washington, D.C. 
Fouche, J. G., and L. Jouve. 1999. "Vanilla planifolia: History, Botany and Culture in Reunion Island." Agronomie 19: 689-703.

Havkin-Frenkel, D., and F. C. Belanger. 2018. Handbook of Vanilla Science and Technology. Wiley-Blackwell, Singapore.

Odoux, E., and M. Grisoni. 2010. Vanilla. CRC Press. 